\title{
THE FIFTH OLIVER BIRD LECTURE \\ BIOLOGICAL CONTROL OF CONCEPTION*
}

\author{
A. S. PARKES \\ National Institute for Medical Research, Mill Hill, London
}

INTRODUCTION

This is the Fifth Oliver Bird Lecture and it is appropriate, therefore, to attempt a rather more general survey than has been the case with the earlier lectures. The Oliver Bird Lecture and the Oliver Bird Prize were instituted to review and stimulate work bearing on the control of conception in man. Such review and stimulation was badly needed. Four years ago, when the Oliver Bird Trust came into being, no organized clinical trials of contraceptive methods were going on in this country, and those working on the physiology of reproduction were giving little thought to possible applications of their work to the control of human fertility. Yet, on a global scale, the need for such control by simple and effective methods was becoming more urgent every year.

In many countries, population is increasing at an unprecedented rate and, what is more, at an accelerating rate. This increase is not due to any sudden increase in human fertility, it is due to the work of medical science in decreasing mortality and increasing the expectation of life at birth in the many parts of the world where the birth-rate is still very high. All animal populations are kept in check by three limiting factors, food supply, disease and enemies, or in human terms by famine, pestilence and war, the traditional scourges of mankind. The relaxation of the limiting factor of disease is enabling mankind at least for a time, to demonstrate that human, like other populations, given the chance, really do tend to increase geometrically, as postulated long ago by Malthus.

Text-fig. 1 takes the story up to 1956 and a world population estimated at 2700 million. The total is now thought to be about 3000 million. Population growth of this kind cannot go on indefinitely; something will happen to stop it. That something will be some limiting factor other than disease, and the human race must decide whether it will be a pleasant or an unpleasant one. Let us hope that an active choice will be made for a fourth and essentially human, and humane, limiting factor, voluntary control, rather than a choice by default for war or famine.

Different countries, of course, are contributing in very different degrees to this population explosion.

Text-fig. 2 shows the patterns of natural increase for Singapore, the U.S. and the U.K. They are not exceptional, each represents a type. Natural increase in Singapore over the last 10 years or so has averaged about 35 per 1000 or $3.5 \%$; in the U.S. about $1.5 \%$ and in U.K. about $0.4 \%$. The smallness of the

* Delivered at the School of Hygiene and Tropical Medicine, London, 20th June, 1961. 


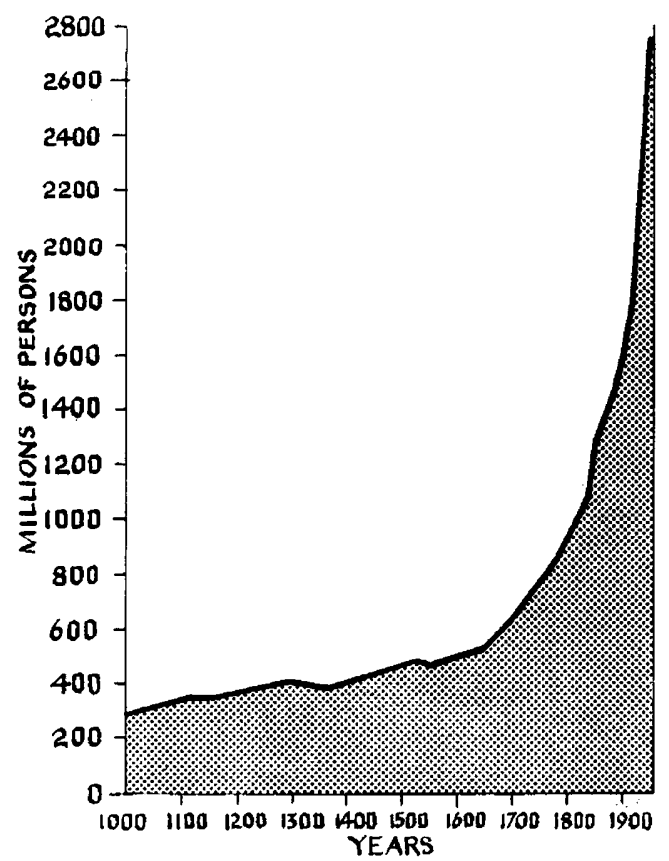

TEXT-FIG. 1. Growth of world population 1000-1956 (Population Bulletin 1957, 13, 135).

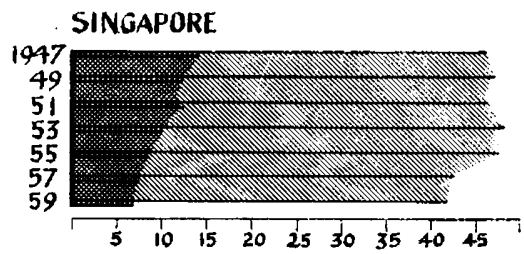

U.S.A.

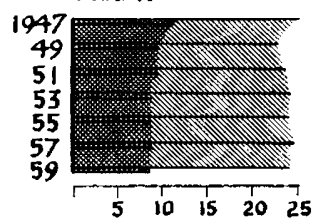

U.K.

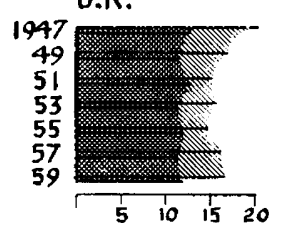

\section{Death rate Birth rate}

Natural Increase

TEXT-FIG. 2. Natural increase in certain populations, as shown by the difference between birth- and death-rates (Population Bulletin 1959, 15, 85). 
natural increase in the U.K. may be judged by the fact that, last year, the unnatural increase due to immigration was $0.6 \%$, half as much again as the average natural increase per year over a decade.

In the U.K., the small natural increase in population now taking place is not, in itself, causing any new problems. The need for improved and more simple methods of birth control arises from practical, aesthetic and eugenic requirements of the individual. In many underdeveloped countries, however, where strenuous efforts to improve the standard of living are being swept away in the rising flood of people, it is imperatively necessary from the national point of view that some simple and effective method of controlling human fertility should become available. There is the further distinction that, from the point of view of the individual, a method must above all be highly reliable, whereas, from the point of view of a nation facing a crippling increase in population, a method might well be useful, even if unreliable for the individual, provided that it decreased the birth-rate overall.

All this raises the question of what we mean by improved methods of contraception. It is, of course, impossible to define an ideal method exactly, and ideal methods would not necessarily be the same in different parts of the world. But at least we can say that an ideal method should be safe and reliable, should involve only infrequent action not contemporaneous with coitus and should be simple enough to be used by anyone sufficiently intelligent to understand the possible results of coitus and to know whether they do or do not want to conceive.

We must also consider another definition.

In the title of this lecture I have used the expression 'biological control' of conception. What exactly does 'biological' mean in this connection? Obviously, it excludes surgical or mechanical obstructions to the processes of reproduction and $I$ want to restrict the meaning still further by excluding the local use of spermicides. These compounds, which were the subject of the First Oliver Bird lecture given by Dr T. Mann (Mann, 1958) are extremely interesting in relation to the biochemistry of spermatozoa, but all types at present known involve local and contemporary application and have, therefore, little potentiality as the basis of an ideal method. In fact, it is difficult to visualize any local method having such potentiality. For practical purposes, therefore, I take 'biological control' to mean control by systemic treatment treatment involving the body as a whole - of which the simplest, of course, is treatment by mouth; in other words, by 'the pill'. Such systemic treatment, however, must be harmless and depend for its effect only on the interruption or suppression of one or more of the biological, biochemical or biophysical events leading to conception.

\section{METHODS OF CONTROL}

\section{OUTLINE OF BIOLOGIGAL POSSIBILITIES}

Prevention of conception by biological means involves one or other of three things: the prevention of the formation or the release of germ cells, in male or female; the prevention of fertilization; or the prevention of implantation of the fertilized egg. (Text-fig. 3). 
The first of these approaches involves the inhibition of spermatogenesis or of ovulation, and has been the subject of a vast amount of work. As to the second, the most obvious way of preventing fertilization of the egg is to avoid intercourse altogether, but there seems little enthusiasm for this method. On the other hand, avoidance of intercourse during the fertile period of the woman, possibly 3 days in all of the menstrual cycle (allowing for the combined survival times of spermatozoa and ovum), the so-called rhythm method, has received a great deal of attention. The pros and cons are well known and need not be discussed here.

The third approach to fertility control, the prevention of implantation, raises an important point of principle. There is no generally accepted definition of the word conception, but in my biological view it must refer not to fertilization but to the implantation of the fertilized egg in the uterus. For instance, a hen is not said to conceive when her egg is fertilized, or to abort when she lays it. On this view, contraception can properly be practised up to the time of implantation. This is a most important point because much interesting work is

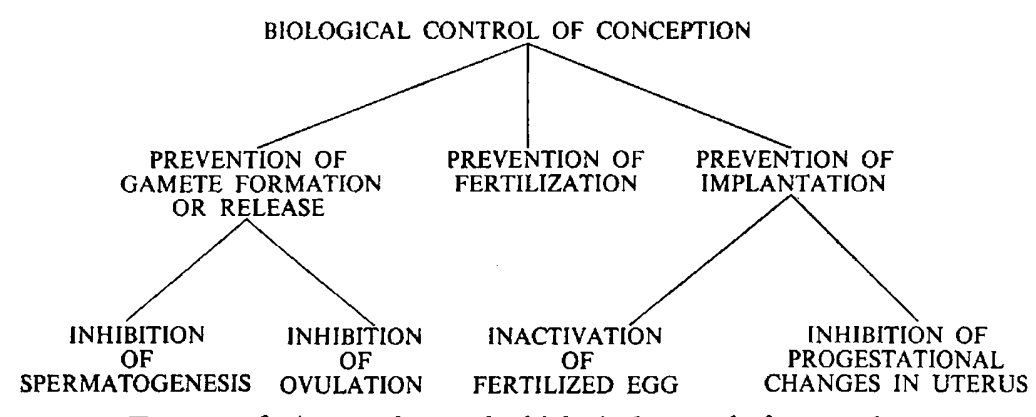

TEXT-Fig. 3. Approaches to the biological control of conception.

now being carried out on the control of implantation. Moreover, a method involving only brief retrospective treatment, presumably during the 3rd week of the cycle, would have great advantages over methods that necessarily anticipate the uncertain contingency of exposure to the risk of pregnancy. Moreover, if there was no interference with the menstrual cycle, it could never be known whether or not a fertilized egg had been present.

\section{INHIBITION OF SPERMATOGENESIS}

In any discussion of regulating male fertility by inhibiting spermatogenesis allowance must be made for the fact that viable spermatozoa are stored in the male tract for a considerable time, so that even the abrupt cessation of spermatogenesis does not cause sterility for some weeks.

\section{Suppression of hypophysial activity}

The simplest way to inhibit spermatogenesis in males is by the administration of gonadal hormones or analogous substances which suppress the secretion of gonad-stimulating hormones by the anterior pituitary body and cause 
atrophic changes in the spermatic tubules, similar to those seen after hypophysectomy. Oestrogens and certain of the orally-active progesterone-like substances are particularly effective (Text-fig. 4), but treatment needs to be almost continuous. Recovery quickly follows cessation of treatment. Moreover, the secretion of ICSH from the pituitary gland is inhibited as well as that of FSH, so that the production of male hormone by the testis is impaired or stopped, with the probable, though not inevitable, impairment of libido. Possibly the addition of androgen to the medication would overcome this difficulty. The principles involved in this method of suppressing fertility are considered later, and a good deal of information was given in a paper by Nelson (1959).

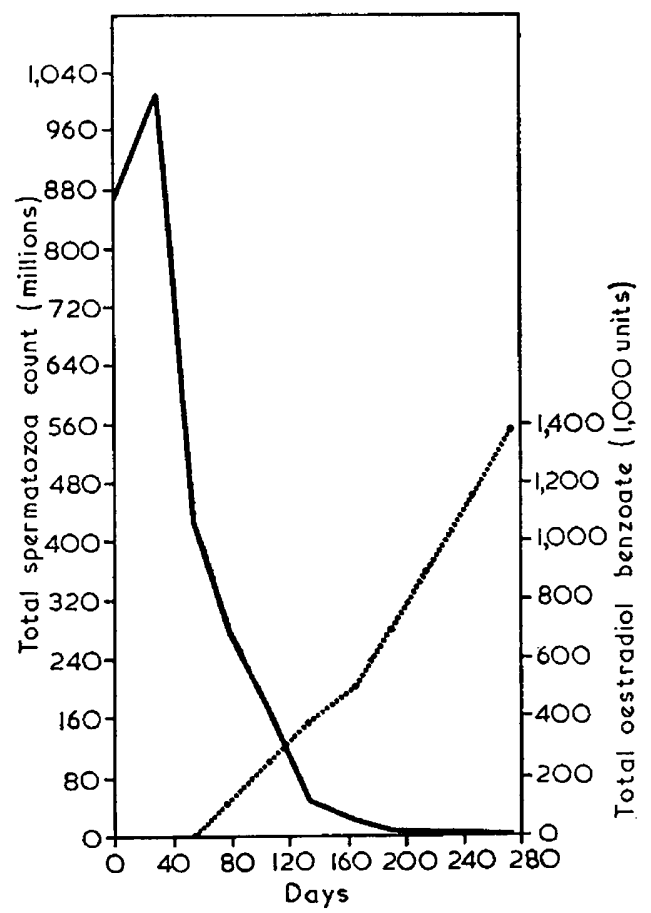

TEXr-FIG. 4. Suppression of spermatogenesis in man by administration of oestrogen (Heckel \& Steinmetz, 1941).

Much thought has been given from time to time to the possibility of obtaining a non-steroidal, non-toxic, and otherwise inactive inhibitor of pituitary gonadotrophic activity, but, so far as I am aware, there is no published report of success in this direction.

\section{Immunological approaches}

Spermatogenesis in laboratory animals can also be inhibited in certain conditions by immunological methods based on inactivation of hypophysial gonadotrophins or on inhibition of spermatogenic activity. The so-called antihormone effects arise from the fact that crude preparations of gonadotrophins are antigenic, and show organ rather than species specificity. For instance, 
crude preparations of ox pituitary injected into rabbits evoke circulating antibodies, and antigonadotrophic sera so obtained will inactivate the endogenous gonadotrophins of both rabbits and rats, and lead to hypotrophy of the gonads, including failure of spermatogenesis (Rowlands, 1937). Comparatively little work has been carried out in the last 20 years on these anti-hormone effects, and I see little immediate hope of their being applied to the control of human fertility.

The direct immunological attack on the testes by the injection of spermatozoa or testis preparations made little headway until adjuvants, which greatly potentiate antigenic activity, came into use. By this technique, Freund and his co-workers (1953) were able to destroy the spermatogenic tissue in guineapigs, using guinea-pig testes plus adjuvant as the antigen. Unfortunately, the adjuvant, consisting of killed bacteria in liquid paraffin, causes a severe local reaction, and further the technique has been found of little value in other animals than guinea-pigs. Interest in this field, however, has been revived by the observation that in a small proportion of sterile men the serum contains antibodies against spermatozoa, so that sterility in such cases could be due to disturbance of spermatogenesis, or to agglutination of mature spermatozoa, caused by the antibodies. Investigation of the factors concerned in the occurrence of such auto-immunization may well enable it to be produced at will and so control male fertility. The whole subject of immunological approaches to fertility control was reviewed by Dr Albert Tyler in the Fourth Oliver Bird Lecture (Tyler, 1961).

\section{Biochemical interference with spermatogenesis}

A most interesting reaction was reported in 1957 by Dr J. Pařízek working in Prague, and was subsequently the subject of the Third Oliver Bird lecture given by him early last year (Paŕízek, 1960). The inhibition of spermatogenesis by most methods is reversible; at worst the tubules remain as visible structures. Pařizek found, however, that the administration of cadmium chloride to rats, in doses not otherwise toxic, caused an immediate and catastrophic breakdown of the tubules and their complete and permanent disappearance as anatomical structures. The interstitial cells were involved in the first wave of destruction, but subsequently regenerated and produced male hormone, as shown by the re-development of the accessory glands. This effect of cadmium is entirely prevented by the simultaneous injection of zinc, and is presumably due, therefore, to the inhibition of some essential function of zinc in testis metabolism. This most interesting observation deserves further study.

Two other series of investigations in this field should be mentioned, $\mathrm{Dr} \mathrm{H}$. Jackson and his colleagues (Jackson, 1959; Jackson, Fox \& Craig, 1961) have made an extensive study of the effect of radiomimetic agents and other chemical substances on spermatogenesis and have indicated the various stages of the process that can be interfered with by the various compounds. This work is of great biological interest, and Dr Jackson was awarded the Oliver Bird Prize for 1960, but there must be some doubt as to the possibility of using radiomimetic substances in man.

The other experiments I want to refer to in this connexion have been carried 
out recently by Carl Heller and his colleagues in the U.S. on a series of diamine compounds notably bis-(dichloracetyl)-diamines tested on animals and man. These substances suppress spermatogenesis (Text-fig. 5), but do not affect the activity of the pituitary gland or Leydig cells of the testis, so that libido is not impaired (Heller, Moore \& Paulsen, 1961). Nelson, however, has recently pointed out that there are some disadvantages to the practical use of these substances (Nelson, 1961).

\section{INHIBITION OF OVULATION}

In the male, spermatozoa are produced continuously in countless millions during the whole of reproductive life. The problem of fertility control in the

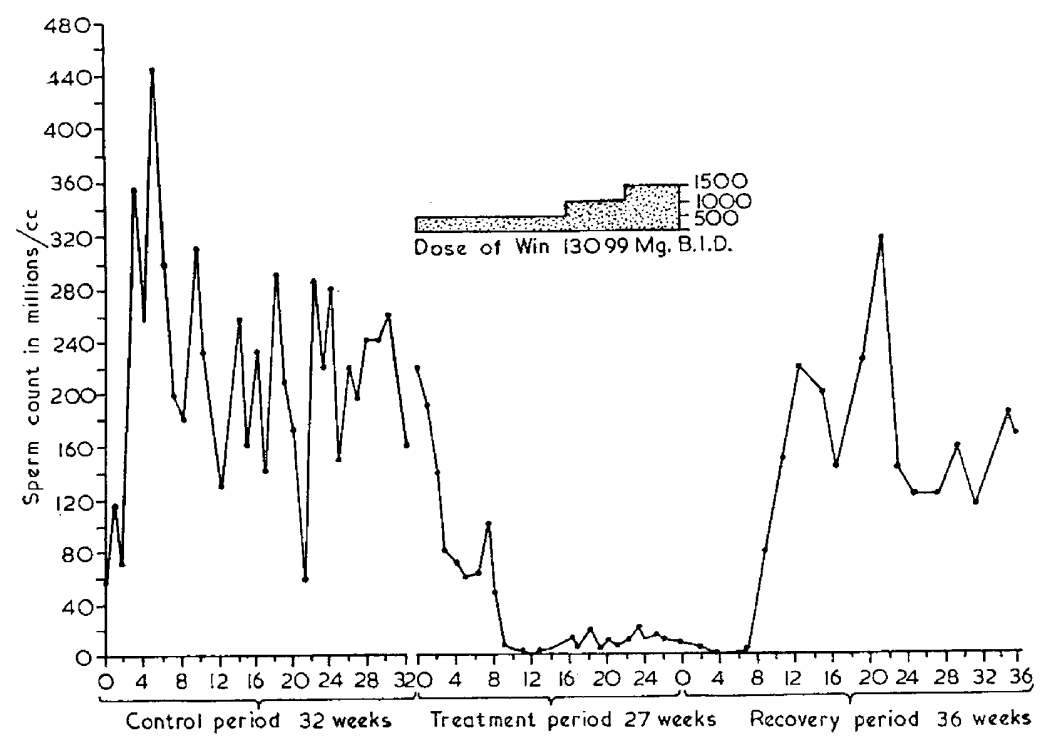

Text-FIG. 5. Inhibition of spermatogenesis in man by administration of bis-(dichloracetyl)-diamine (Heller, Moore \& Paulsen, 1961).

male thus turns on arresting and reviving this production at will, and making due allowance for the fact that mature spermatozoa are stored in the male tract for some weeks. In the female, the situation is quite different. The ovarian eggs are formed early in life, and thereafter the egg population is subject to continuous wastage by ovulation and atresia. The problem in the female, therefore, is not to control gamete formation, but to suppress or permit at will the discharge of eggs from the ovary.

This brings us to fertility control by inhibition of ovulation and to the subject of the Pincus pill. I want to say immediately that there is nothing mysterious or magical about the Pincus pill. Thirty years ago, soon after the discovery of the hypophysial gonadotrophic hormones, it was recognized that the relationship between the anterior pituitary body and the gonads must be reciprocal and that the gonads must be able to regulate pituitary activity to 
prevent their being over- or under-stimulated. This feed-back mechanism, as it is now known, depends on the fact that an excess of gonad hormone in the circulation, such as would result from over-stimulation of the gonad, depresses pituitary gonadotrophic activity, and that conversely a low level of gonad hormone in the circulation, such as would result from under-stimulation, increases it. The chief evidence for this relationship was obtained by creating an artificial excess by the injection of gonad hormones and the creation of an artificial shortage by ovariectomy.

This pituitary-depressing effect is particularly powerful in the case of the oestrogens and it was known 15 years ago that administration of oestrogen early in the menstrual cycle would depress pituitary activity sufficiently to inhibit ovulation. This technique was in fact used to prevent ovulation, and thence the appearance of the corpus luteum, in cases of chronic dysmenorrhoea (Bishop \& Orti, 1952), but it was not developed for fertility control because of

TABLE 1

INCIDENCE OF PREGNANCIES IN 265 PUERTO RICAN SUBJEGTS TAKING TWENTY TABLETS OF 10 MG NORETHYNODREL PLUS $0 \cdot 2$ MG OESTROGEN DURING EACH MENSTRUAL CYCLE (From Pincus, 1958)

\begin{tabular}{l|c|c}
\hline \multicolumn{1}{c|}{$\begin{array}{c}\text { No. tablets } \\
\text { missed }\end{array}$} & $\begin{array}{c}\text { No. } \\
\text { cycles }\end{array}$ & $\begin{array}{c}\text { Pregnancies per } \\
100 \text { woman-years }\end{array}$ \\
\hline Premedication & - & $62 \cdot 5 \pm 1 \cdot 35$ \\
0 to 5 & 1279 & $0 \cdot 0$ \\
6 to 19 & 282 & $9 \cdot 2$ \\
All medication & 151 & $25 \cdot 9$ \\
& 1712 & $3 \cdot 8$ \\
\hline
\end{tabular}

lingering doubts about the effect of frequent administration of large amounts of oestrogen.

The second ovarian hormone-progesterone-also had the pituitarydepressing effect to a lesser extent, but this naturally-occurring hormone being inactive by mouth was also unsuitable for the routine suppression of ovulation. The first orally-active progesterone-like substance, produced more than 20 years ago, afterwards known as ethisterone, was only feebly active; it remained for a mass of chemical work in the early 1950s to produce a series of compounds some of them based on ethisterone with intense progesterone-like activity and highly effective by mouth. Gregory Pincus of the Worcester Foundation in the U.S. recognized the possibility of using these substances for fertility control by inhibition of ovulation, and initiated a long series of laboratory experiments and clinical trials which have completely vindicated his thesis. Dr Pincus received the Oliver Bird Prize for 1957 and he described the basic results of his work in the Second Oliver Bird Lecture which was given in 1958 (Pincus, 1958), and from which Table 1 is reproduced because of its historic interest.

At present, we are on the verge of at least a small-scale routine use of the 
technique. Great credit must go to Pincus for his vision, and for being the driving force behind this outstanding field experiment in human biology. I hope my old friend Gregory Pincus will forgive me when I say that it is appropriate, as well as convenient, to refer to preparations of orally active progestagens used for the purpose of fertility control as Pincus pills, to distinguish them from other contraceptive pills, having an entirely different mode of action, which will certainly be forthcoming.

The outstanding problem of the Pincus pill is not as to whether it works but as to the extent of uncomfortable side-effects, and of possible dangers arising from the long-term frustration of the focal gland of the endocrine system. It has, moreover, the great disadvantage that ovulation must be suppressed, not merely postponed, and this involves medication during the greater part of the menstrual cycle. I cannot speak authoritatively as to the general acceptability of the method but I have doubts as to the global applicability of a method involving the swallowing of twenty pills to a set timetable during each menstrual cycle for the whole of reproductive life.

And here I have a suggestion to make. There is little doubt that preparations suitable for use in the male will be developed, based either on inhibition of the pituitary or on direct inhibition of spermatogenesis. My suggestion is that work on the male should be pushed ahead with the idea that husband and wife might take, say, yearly shifts in consuming pills, a period of overlap, of a month or so, being necessary when the change was made from female to male. Such alternation would presumably minimize the possible dangers of long-term treatment of one individual.

There is one final point I must emphasize about the use of progestagens to inhibit ovulation. The effect is not the monopoly of any one compound some dozens of progestagens in all have been described and most of them are pituitary inhibitors to a greater or lesser extent. Pincus originally investigated four of the compounds and chose for further study norethynodrel with a small admixture of oestrogen, manufactured by Searle's and known as 'Enovid' or 'Enavid'. Pincus's main wor khas been carried out with this compound. This preparation has now appeared on the English market for contraceptive purposes as 'Conovid' and is being used in the Birmingham trial. Two other preparations, however, are being clinically tested in this country under the auspices of the Council for the Investigation of Fertility Control, the body set up by the Oliver Bird Trust for this purpose. One is a Schering product containing norethisterone acetate and oestrogen. The second is a B.D.H. product containing an oral progestagen more closely related to progesterone, also in combination with oestrogen, to be known commercially as 'Parvol'.

\section{PREVENTION OF FERTILIZATION}

I want now to turn to the prevention of fertilization in circumstances where both male and female are producing viable germ cells. In other words, the prevention of effective contact between spermatozoon and ovum.

Control of cervical mucus

One possibility that has not been explored adequately is the control of the 
nature of the cervical mucus. During the normal cycle the cervical mucus is thin and runny about the time of ovulation, and tough and viscous to a varying extent at other times. There is good reason to suppose that the mucus is much more easily penetrated by spermatozoa at mid-cycle than it is at other times, and that the changes are under the control of oestrogens and progesterone (see Zondek, 1954). An obvious suggestion is that treatment with progestagens should be directed to making the cervical mucus impenetrable at all stages of the cycle. It may well be that the ovulation-inhibiting effect of the oral progestagens already referred to is reinforced by changes in the cervical mucus which bar the way to spermatozoa.

\section{Inhibition of hyaluronidase}

At one time it was thought that the enzyme hyaluronidase, carried by the spermatozoon, played an essential part in the preliminaries to fertilization and that the use of hyaluronidase inhibitors would therefore prevent fertilization. Such inhibitors mixed with rabbit semen before insemination certainly have this effect. Unfortunately, the precise reason for this result is not known and there are reliable indications that it cannot be reproduced by the systemic administration of hyaluronidase inhibitors.

\section{Immunization against spermatozoa}

The idea of immunizing the female against spermatozoa, as against other foreign bodies, and thence against pregnancy has long been attractive. The idea is based on the fact that spermatozoa are strongly antigenic when injected into animals of another species and evoke the production of antibodies which cause agglutination of spermatozoa in vitro. Moreover, the antigenicity is organ specific rather than species specific so that the serum of a rabbit injected with guinea-pig spermatozoa will agglutinate both rabbit and guinea-pig spermatozoa in vitro, but will not react with guinea-pig serum. These reactions are most interesting to watch (see Smith, 1949). The difficulty, however, has been to obtain an effective concentration of antibodies at the necessary site of action, namely within the female reproductive tract. Possibly, spermatozoa in the reproductive tract are protected by antagglutins of the kind described by Lindahl \& Nilsson (1954). But whatever the reason, the fact remains that sporadic experiments over more than 30 years failed to produce any clear demonstration of the sterilization of females by the injection of spermatozoa of a different species. Recently, attempts by Katsh (1959) and others to immunize females against spermatozoa with the help of adjuvants have been more superficially successful, but the results seem to have depended not on lack of fertilization but on the occurrence of abortion.

Interest in this field has also been revived by investigations into the fate of the enormous numbers of redundant spermatozoa that enter the female tract. Some at least appear to penetrate the uterine or tubal epithelium, but whether or not they could effect iso-immunization of the female by so doing is a matter for debate. There are observations suggesting that in certain circumstances they might do so. First, insemination of spermatozoa from a different species may cause the appearance of circulating antibodies, as shown by my colleague 
Dr Edwards (Edwards, 1960) and others. Second, there is the most interesting observation that female mice of the G57 strain, which do not normally accept skin grafts from males even of the same strain, will do so after a series of fertile matings with them (Prehn, 1960). I find this a most thought-provoking observation.

\section{PREVENTION OF IMPLANTATION}

Assuming that the egg has been fertilized, what can be done to prevent implantation, that is, in my definition to prevent conception?

\section{Inactivation of the fertilized egg}

First of all, I want to deal with the inactivation of the egg in the Fallopian tube, an effect exerted by several compounds when given in appropriate dosage at the proper time. One of these substances, known as MER 25, was investigated by Segal \& Nelson (1958). This compound, administered to rats after mating, often inhibited implantation in a single dose. It did so regularly if given over the whole period when the fertilized eggs were in the Fallopian tube. The work of Segal \& Nelson showed clearly that the effect was due to interference with the normal segmentation of the egg in the tube and did not depend on adverse changes in the uterus. Unfortunately, it seems that MER 25 was hallucinogenic when tested clinically - a somewhat unfortunate property for a contraceptive. However, I understand that a far more active analogue, free from such sideeffects, is now under test. I feel we are likely to hear a great deal more of compounds of this type.

\section{Inhibition of progestational proliferation or sensitivity}

The second main method of preventing implantation of the fertilized egg is to interfere with the necessary preliminary changes in the uterus. This may be done by hormonal, biochemical, pharmacological or even neurohumoral methods.

The progestational proliferation or sensitization of the uterine endometrium, necessary for implantation of the fertilized egg, depends on a delicate balance between oestrogens and progesterone. Disturbance of this balance prevents these changes and implantation does not take place. This effect can usually be brought about by administering oestrogen shortly after ovulation and it has been known for 30 years or so that disturbance of the balance in this way prevents the establishment of pregnancy in experimental animals. I am not aware that any determined effort has been made to investigate this possibility in man. Excess progesterone may also upset the balance and make uterine conditions unsuitable for implantation. An effect of this kind is possibly yet a third line of defence provided by the Pincus pill. Another approach to this problem is not to provide an excess of one or other hormone, but to cause a deficiency of one or the other. Emmens and his colleagues (1959), for instance, have shown that dimethylstilboestrol, a close relative of diethylstilboestrol, although a weak oestrogen in its own right, is a competitive inhibitor of the more active oestrogens (Text-fig. 6), and that its overall effect in vivo is to 
inhibit endogenous oestrogens and thus prevent implantation. Clinical trials based on this observation are now beginning.

Other methods of preventing implantation are based on the fact that the necessary growth or other changes in the endometrium involve metabolic changes that can be prevented or interfered with by various inhibitors. Thus, folic acid is necessary for oestrogen-induced growth, which can therefore be inhibited by folic-acid inhibitors. Unfortunately, the inhibition of oestrogeninduced growth is only one of the many actions of folic-acid inhibitors, and the administration of compounds such as aminopterin when pregnancy is established leads to abortion or foetal abnormality. Inhibitors of various enzyme systems are also known to prevent the progestational changes in the uterus necessary for the implantation of the fertilized egg.

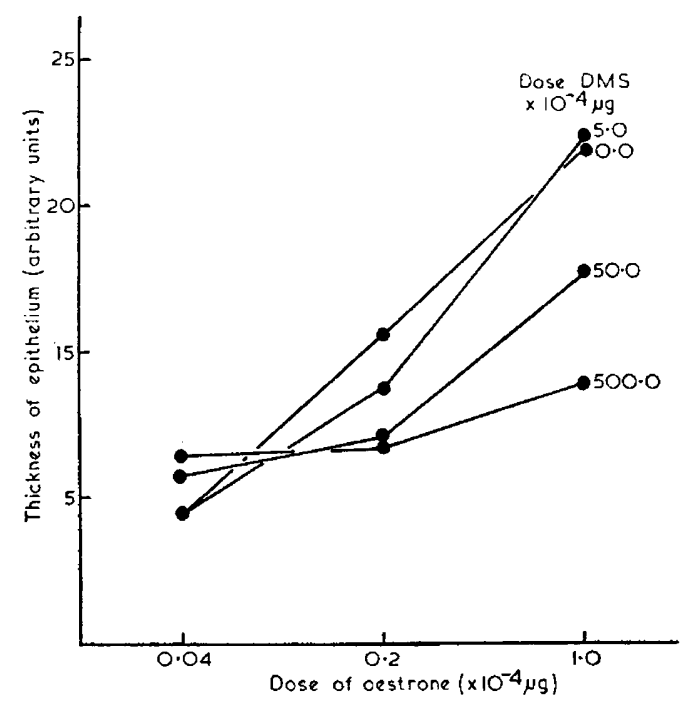

Text-FIG. 6. Inhibition of oestrone-induced epithelial growth by dimethylstilboestrol (Emmens, Cox \& Martin, 1959).

What may be called pharmacological methods of inhibiting progestational proliferation depend on Shelesnyak's observation (1957), for which he received the Oliver Bird Prize for 1958, that histamine is involved in decidual reactions, which can therefore be provoked when they would not otherwise occur by histamine releasors, and prevented when they would otherwise occur by histamine inhibitors. Histamine release in the uterus and consequently decidual reactions, can be produced by systemic administration of releasors, but, unfortunately, the inhibitory effect has so far only been obtained by local application in the uterus.

Lastly, I want to refer to the remarkable observation of my colleague Miss Bruce that the majority of newly-mated female mice fail to become pregnant if exposed to the proximity of males of a different strain. Analysis of the effect has shown (a) that the operative factor is the smell of the alien males, and $(b)$ that the hormonal cause is failure of the anterior pituitary body to maintain the corpora lutea in the ovary and thence failure of the uterus to undergo the 
changes necessary for implantation. The Bruce effect is thus a neurohumoral block to implantation. Not only does pregnancy fail, but also the pseudopregnancy that would normally follow sterile mating in the mouse. The end result is that the rapid cycle characteristic of the unmated female continues as though mating had not taken place - an ideal arrangement. This work is reviewed and its general biological implications discussed by Parkes \& Bruce (1961). So far, all efforts to bottle the smell of the alien males have failed and work has not yet been extended to other species, but this olfactory block to implantation is clearly of great interest and potentiality. I am not suggesting that a contraceptive perfume is just round the corner, but at least such an attractive idea is no longer quite incredible. Miss Bruce received the Oliver Bird Prize for 1959.

\section{CONCLUSION}

What of the future? The Pincus pill is evidently going to have at least a temporary vogue, but I cannot see such a cumbersome method being the ultimate answer. Nor is an ideal method likely to appear as the result of some dramatic advance. More likely, one approach will be superseded by another, so that, as with other forms of therapy, methods will be improved gradually.

If I had to make a guess, I should say that a pill for males will come next, though whether in this country the average man could be persuaded to use it, is not certain. As another guess, I should say that prevention of implantation or immunization will follow. The latter, if effective over a reasonably long period, would be particularly valuable in underdeveloped countries, where continuous, frequent, or expensive medication presents special difficulties.

Finally, we must always remember that the best methods will be of little value demographically unless people can be persuaded to use them, and this may not be easy in countries conditioned to the idea of a high birth-rate and a high death-rate, and in which public-health measures have reduced the death-rate so rapidly that the social background has had little chance to adjust itself. But at least we should ensure that both demographic and personal aspects of human reproduction are as widely understood as possible, and that simple and reliable methods of fertility control are available for those who wish to use them. In this we have far to go. Established methods of fertility control, being archaic in principle, are a disgrace to science in this age of spectacular technical achievement. In general, I am all in favour of science pushing on all the time in every direction, but I sometimes think that the further exploration of inner man would be more immediately useful than the exploration of outer space.

\section{REFERENCES}

Bishop, P. M. F. \& Orti, E. (1952) The endocrine treatment of dysmenorrhoca. Proc. roy. Soc. Med. $45,803$.

EDWARDS, R. G. (1960) Antigenicity of rabbit semen, bull semen and egg yolk after intravaginal or intramuscular injections into female rabbits. F. Reprod. Fertil. 1, 385.

Emmens, G. W., Cox, R. I. \& Martin, L. (1959) Oestrogen inhibitors of the stilboestrol series. F. Endocrin. 18, 372. 
Freund, J., Lipton, M. M. \& Thompson, G. E. (1953) Aspermatogenesis in the guinea-pig induced by testicular tissue and adjuvants. F. exp. Med. 97, 711.

Heckel, N. J. \& Steinmetz, C. R. (1941) The effect of female sex hormone on the function of the human testis. F. Urol. 46, 319.

Heller, C. G., Moore, D. J. \& Paulsen, C. A. (1961) Suppression of spermatogenesis and chronic toxicity in men of a new series of bis-(dichloracetyl)-diamines. Toxicol. appl. Pharmacol. 3, 1.

Jackson, H. (1959) Antifertility substances. Pharmacol. Rev. 11, 135.

JACKson, H., Fox, B. W. \& CRAIG, A. W. (1961) Antifertility substances and their assessment in the male rodent. F. Reprod. Fertil. 2, 447.

KATsH, S. (1959) Infertility in female guinea-pigs induced by injection of homologous sperm. Amer. 7. Obstet. Gynec. 78, 276.

Lindahl, P. E. \& Nilsson, A. (1954) On the occurrence of sperm antagglutin in the female rabbit. Ark. Zoöl. 7, 223.

ManN, T. (1958) Biochemical basis of spermicidal activity. Studies on Fertility, 9, 3.

Nelson, W. O. (1959) Studies on the inhibition of spermatogenesis. Proc. VIth int. Conf. Family Planning, New Delhi, p. 143.

NeLson, W. O. (1961) Inhibition of spermatogenesis with bis-(dichloracetyl)-diamines. F. Reprod. Fertil. 2, 518.

Paḱzizek, J. (1960) Sterilization of the male by cadmium salts. F. Reprod. Fertil. 1, 294.

PARKEs, A. S. \& Bruce, H. M. (1961) Olfactory stimuli in mammalian reproduction. Science, 134, 1049.

Pincus, G. (1958) Fertility control with oral medication. Studies on Fertility, 10, 3.

PREHN, R. T. (1960) Specific homograft tolerance induced by successive matings and implications concerning choriocarcinoma. 7. nat. Cancer Inst. 25, 883.

Rowlands, I. W. (1937) The effect of antigonadotrophic serum on the reproductive organs of the normal animal. Proc. roy. Soc., B. 121, 517.

Segal, S. T. \& Nelson, W. O. (1958) An orally active compound with anti-fertility effects in rats. Proc. Soc. exp. Biol. N.Y. 98, 431.

Shelesnyak, M. C. (1957) Some experimental studies on the mechanism of implantation in the rat. Recent Progr. Hormone Res. 13, 269.

Sмrтh, A. U. (1949) Some antigenic properties of mammalian spermatozoa. Proc. roy. Soc., B. 136, 46.

TYLER, A. (1961) Approaches to the control of fertility based on immunological phenomena. F. Reprod. Fertil. 2, 473.

Zondek, B. (1954) Some problems related to ovarian function and to pregnancy. Recent Progr. Hormone Res. 10, 395. 